\title{
Ergiyik Harmanlama ile Üretilen Poli(metil metakrilat) (PMMA)/Cam Fiber Kompozitlerin Mekanik ve Tribolojik Özelliklerinin İncelenmesi
}

\author{
Lemiye Atabek Savaş, ${ }^{1, *}$ \\ ${ }^{1 *}$ Erciyes Üniversitesi, Mühendislik Fakültesi, Malzeme Bilimi ve Mühendisliği Bölümü, Kayseri, 38039, Türkiye (ORCID: 0000- \\ 0002-6504-5846) atabek1@erciyes.edu.tr
}

(İlk Geliş Tarihi 12.07.2021 ve Kabul Tarihi 04.08.2021)

(DOI: 10.29228/JCHAR.52084)

ATIF: Atabek Savaş, L, Ergiyik Harmanlama ile Üretilen Poli(metil metakrilat) (PMMA)/Cam Fiber Kompozitlerin Mekanik ve Tribolojik Özelliklerinin İncelenmesi, Journal of Characterization, (1)3, 104$113,2021$.

$\ddot{O} z$

Bu çalışmada, ağırlıkça farklı yüzdelerde (\%5-10-20-30) cam fiber içeren poli(metil metakrilat) (PMMA) matrisli kompozitlerin mekanik ve aşınma direnci özellikleri araştırılmıştır. Üretimde çift vidalı bir ekstrüder kullanılarak ergiyik harmanlama yöntemi tercih edilmiş olup, test numunelerinin üretiminde ise enjeksiyon kalıplamadan faydalanılmıştır. Kompozitlerin mekanik özellikleri 3-nokta eğme ve Shore D sertlik ölçümleri ile, aşınma özellikleri ise özel üretim bir ball-on-disk kuru kayma aşınma test cihazı kullanılarak incelenmiştir. Benzer şartlarda şekillendirilen saf PMMA da aynı testlerde kontrol numunesi olarak kullanılmış ve cam fiber konsantrasyonuna bağlı olarak bahsedilen testlerin sonuçları yorumlanmıştır. En yüksek eğme gerilmesi ve elastiklik modülü değerlerine (sırasıyla $121 \mathrm{MPa}$ ve 7354 $\mathrm{MPa}$ \% 30 cam fiber içeren PM30 numunesi ile ulaşılmıştır. Benzer şekilde, yüksek sertlik, düşük sürtünme ve düşük aşınma oranı gibi özellikler $\% 20$ ve $\% 30$ cam fiber içeren kompozitlerde gözlenmiş̧tir. Bu durum, cam fiber içeriğindeki artıșın kompozit rijitliğini arttırması ayrıca yorulma aşınması direncinin de iyileştirmesi ile ilişkilendirilmiştir.

Anahtar Kelimeler: Poli(metil metakrilat), cam fiber, mekanik özellikler, aşınma direnci.

\section{Investigation of Tribological and Mechanical Properties of Poly(methyl methacrylate) (PMMA)/ Glass Fiber Composites Prepared by Melt Blending}




\begin{abstract}
In this study, mechanical and wear resistance properties of poly(methyl methacrylate) (PMMA) matrix composites containing glass fiber in different weight percentages (5-10-20-30\%) were investigated. Melt blending method was preferred using a twin screw extruder in production, and injection molding was used in the production of test samples. The mechanical properties of the composites were investigated by 3-point bending and Shore $\mathrm{D}$ hardness measurements, and the wear properties were examined using a custom-made ball-on-disk dry sliding wear tester. Pure PMMA shaped under similar conditions was also used as a control sample in the same tests and the results of the mentioned tests were interpreted depending on the glass fiber concentration. The highest bending stress and modulus of elasticity values (121 MPa and $7354 \mathrm{MPa}$, respectively) were obtained with PM30 sample containing 30\% glass fiber. Similarly, properties such as high hardness, low friction and low wear rate were observed in composites containing $20 \%$ and $30 \%$ glass fiber. This situation was associated with the increase in the glass fiber content, increasing the stiffness of the composite and also improving the fatigue wear resistance.
\end{abstract}

Keywords: Polymethylmethacrylate, glass fiber, mechanical properties, wear resistance.

\title{
1. Giriş
}

Poli(metil metakrilat) (PMMA), sert, rijit ve şeffaf bir polimer olup farklı uygulamalarda kullanım alanı bulan bir malzemedir [1]. Diğer termoplastiklere göre atmosfer direncinin yüksek olması ve biyomedikal uygulamalarda kullanılabilmesi bir diğer avantajıdır [2]. Sera tavanları, otomotiv sanayi, gösterge muhafazaları, rüzgarlık ve ayna yuvaları, direk kaplaması, polimer beton, çatı yalıtım sistemleri, elektronik devre kartları ve tesisatlarda kullanım alanı bulan bir polimerdir. Sıvı monomerle karışıtırılarak daha çok diş hekimliğinde protez kaide üretiminde de kullanım alanı bulmaktadır $[3,4,5]$. Bu tür uygulamalarda cam fiber takviyesi ile birlikte mukavemet ve yorulma direnci artışı elde edildiği rapor edilmiştir [3,5-7]. Garoushi ve ark. [6] yaptıkları çalışmada $3 \mathrm{~mm}$ boyunda cam fiberlerle takviyelendirdikleri PMMA reçine esaslı kompozitlerde standart ürünlere göre yüksek eğme mukavemeti, eğme modülü ve tokluk değerlerine ulaşmışlardır. PMMA'nın cam fiberle birlikte yüksek modül ve mukavemet avantajı elde ettiğini Cousins ve ark. [8] da göstermiştir. E-cam fiberinin $70 \mathrm{GPa}{ }^{\prime} l ı k$ çekme modülü, kompozitlerinin mukavemet artışında önemli olan bir parametredir [9].

Uzun cam fiberlerle elde edilen mukavemet özellikleri de (örneğin pultrüzyon işleminden elde edilen) kısa fiber takviyeli kompozitlere göre daha yüksek bulunmuştur. Bir polimer matris ile cam fiber gibi inorganik dolgu maddeleri arasındaki arayüzey özellikleri kompozitlerin performansında kritik bir rol oynamaktadır [2]. PMMA'nın mekanik özelliklerinin iyileştirilmesi için farklı takviyelerden de faydalanılmaktadır. Tek ve çok duvarlı karbon nanotüplerin takviye olarak kullanıldığı PMMA nanokompozitlerinde mekanik ve elektriksel özelliklerde gelişmeler elde edilmiştir [10]. Threepopnatkul ve ark. [11] yaptıkları çalışmada ise poliüretan ile katkılandırılmış ve alkali ve silan yüzey işlemine tabi tutulmuş sisal fiberle takviyelendirilmiş PMMA matrisli kompozitlerde saf karışıma göre eğme mukavemeti, eğme modülü ve darbe mukavemetinde iyileşmeler tespit etmişlerdir. Polietilen fiberlerin (PEF) cam fiberle birlikte PMMA matrisli kompozitlerde aynı anda kullanıldı̆̆ mevcuttur [12].

Jang ve ark. [1] yaptıkları çalışmada PMMA reçine ve cam fiber mat kullanarak fonksiyonel olarak kademelendirilmiş malzeme (fgm) yapısında kompozit üretmişlerdir. Cam fiber takviyeli epoksi kompozitlerde PMMA'nın matris karışımı olarak kullanıldığı bir çalışma da mevcut olup, PMMA'nın molekül ağırlığına göre farklı matris ve ara yüzey yapıları elde edilmiştir [13]. Cousins ve ark. [14] PLA/PMMA polimer karışımlarına cam elyaf ilavesinin malzeme özelliklerini iyileştirdiğini göstermişlerdir. Karışım sistemine cam elyaf ilavesi ile darbe dayanımı \%110, çekme modülü ortalama $\% 210$, kopma gerilimi \%82 ve tokluk \%63 artmıştır. Sonuç olarak cam fiber, PMMA matrisli kompozitlerde üstün mekanik özellikler sunmakta olup, aşınma direnci için de ümit vadetmektedir.

Yapılan literatür araştırmasında ergiyik harmanlama yöntemi ile üretilen PMMA/cam fiber kompozitlerin tribolojik özelliklerinin incelendiği bir çalışmaya rastlanılmamıştır. Kullanılan PMMA daha çok reçine formunda olup, bu tür malzeme daha çok diş hekimliğinde protez kaide yapımında kullanılmaktadır. Bu çalışma kapsamında ağırlıkça farklı yüzdelerde (\%5-10-20-30) cam fiber içeren PMMA matrisli kompozitler, saf PMMA peletlerin ve cam fiberin bir ekstrüder makinesinde 
karıştıılmasıyla üretilmiştir. Mekanik ve tribolojik testlerde kullanılacak numunelerin üretilebilmesi için kompozit peletler ilave bir enjeksiyon kalıplama işlemine tabi tutulmuşlardır. 3-nokta eğme, Shore D ve ball-on-disk aşınma testi sonuçları, cam fiber konsantrasyonu ve ayrıca birbirleriyle de mukayese edilerek yorumlanmış, üretilen kompozitlerin kullanımı ile ilgili önerilerde bulunulmuştur.

\section{Materyal ve Metot}

\subsection{Malzemeler}

Çalışmada kullanılan poli(metil metakrilat) (PMMA) peletler UltraPolymers'den (Diakon CLG356) temin edilmişlerdir. Yoğunluğu $1.18 \mathrm{~g} / \mathrm{cm}^{3}$, kütle akış hızı (MFR) $15 \mathrm{~g} / 10$ dak ve çekme gerilmesi 75.0 MPa'dır. Cam fiberler $5 \mathrm{~mm}$ boyunda kırpılmış halde temin edilmiştir. Karıştırmadan önce PMMA peletler ve cam fiber etüvde $90^{\circ} \mathrm{C}$ 'de 24 sa kurutulmuş ve içerdikleri nem yapıdan uzaklaştırılmıştır. PMMA/cam fiber kompozitler ergiyik harmanlama yöntemi ile vidaları aynı yönde dönen (100 dev/dak) çift vidalı bir ekstrüzyon makinesi kullanılarak (Gülnar; Türkiye) üretilmişlerdir. Ekstrüzyon makinesinin vida çapı $D=12 \mathrm{~mm}$, vida boyu/vida çapı $L / D$ oranı ise 24'tür. Makinenin kontrol edilebilen 6 adet sıcaklık bölgesi cihaz girişinden kalıp çıkışına doğru 40, 180, 185, 190, 210 ve $215^{\circ} \mathrm{C}$ olacak şekilde ayarlanmıştır. Kalıptan çubuk formunda çıkan viskoz kompozit kalıp çıkışına yerleştirilmiş oda sıcaklı̆̆ındaki bir su banyosundan geçirilerek katılaştırılmış ve ardından freze bıçaklı bir kırpıcıdan geçirilerek tekrar pelet formuna getirilmiş̧tir. Kompozit peletler kalıplamadan önce tekrar etüvde $90{ }^{\circ} \mathrm{C}$ 'de 24 sa kurutulmuş ve hemen ardından $12 \mathrm{~mL}$ masa üstü bir mikro-enjeksiyon kalıplama makinesi kullanılarak (Xplore IM 12, Hollanda) standart test numuneleri haline getirilmişlerdir. Enjeksiyon kalıplama makinesinde kullanılan kovan ve kalıp sıcaklıkları sırasıyla $220{ }^{\circ} \mathrm{C}$ ve $25^{\circ} \mathrm{C}$ 'dir. Enjeksiyon için basınç 7 bar'da sabit tutulmuştur. Saf PMMA peletler de kontrol numunesi olarak kullanmak amacıyla aynı işlemlerden geçirilerek numune formunda kalıplanmış olup bundan sonra PM0 olarak adlandırılacaktır. PMx olarak ifade edilen numune kodlarında kullanılan " $x$ " değeri cam fiber bileşimini (5-10-20-30) göstermektedir (Tablo 1).

Tablo 1. Çalışmada kullanılan numunelerin bileşimi

\begin{tabular}{lcc}
\hline Numune Kodu & PMMA (ağ.\%) & Cam fiber (ağ.\%) \\
\hline PM0 & 100 & 0 \\
PM5 & 95 & 5 \\
PM10 & 90 & 10 \\
PM20 & 80 & 20 \\
PM30 & 70 & 30 \\
\hline
\end{tabular}

\subsection{Mekanik Testler}

Kompozit numunelere mekanik test olarak 3-nokta eğme ve sertlik testleri uygulanmıştır. 3-nokta eğme testleri ASTM 790 standardına uygun olarak $5 \mathrm{kN}$ yükleme kapasiteli bir çekme-basma test cihazında (Devotrans GP/R/DNN/CKS III, Türkiye) gerçekleştirilmiştir. Kullanılan dikdörtgen kesitli numune ölçüleri 12.7 x $125 \times 3.2 \mathrm{~mm}^{3}$ olup, mesnetler arası mesafe $55 \mathrm{~mm}$ olacak şekilde ayarlanmıştır. Eğme hızı tüm testler için $2.5 \mathrm{~mm} /$ dak olarak seçilmiştir. Testler $25 \pm 2{ }^{\circ} \mathrm{C}^{\prime}$ lik sıcaklıkta gerçekleștirilmiş olup 3 ölçümün ortalaması alınarak sonuçlar grafik halinde sunulmuştur. Kompozit sertlikleri dijital bir Shore D sertlik ölçüm cihazı (Bareiss HPE II, Almanya) kullanılarak ASTM D2240 standardına uygun şekilde ölçülmüştür. Numunelerin farklı bölgelerinden en az 7 ölçüm alınarak ortalamaları alınmış ve bileşime göre değişimleri grafik halinde ilerleyen bölümlerde paylaşılmıştır.

\subsection{Aşınma Testleri}

Aşınma testleri özel üretim bir ball-on-disk aşınma test cihazı kullanılarak kuru kayma şartlarında ASTM G99 standardına uygun olarak gerçekleştirilmiştir. Şekil 1'de görüldüğü gibi test numunelerinin yüzeyleri yere dik olarak konumlandırılmış ve yükleme ise yere paralel olarak gerçekleştirilmiştir. Bu şekilde aşınma ürünlerinin aşınma yolu üzerinde kalmaması ve üçüncü eleman olarak abrazif etkide bulunmasının azaltılması amaçlanmıştır. Bu şekilde çalışan benzer aşınma test sistemlerine literatürde rastlamak mümkündür. $30 \mathrm{~mm}$ çap ve $8 \mathrm{~mm}$ kalınlığa sahip silindir şeklindeki test numuneleri enjeksiyon 
kalıplama ile üretilmiştir. Numunelerin aşınma testine tabi tutulacak yüzeyleri $\mathrm{R}_{\mathrm{a}} \approx 0.20 \mu \mathrm{m}$ pürüzlülüğe ulaşılıncaya kadar su zımparasında kademeli olarak parlatılmışıtır. Çalışmada yüksek sertlik ve kimyasal kararlılık avantajlarından dolayı $ø 5 \mathrm{~mm}$ silisyum nitrür $\left(\mathrm{Si}_{3} \mathrm{~N}_{4}\right)$ bilyeler aşındırıcı olarak kullanılmıştır. Bilyeler, Şekil 1'de görüldüğü gibi bir tutucuya bağlanmış ve temas esnasında dönmeleri engellenmiştir. $\mathrm{Bu}$ şekilde kayma sürtünmesi elde edilebilmiştir. Tutucuya dik olarak bağlanan bir yük ölçer ile sürtünme kuvvetleri anlık olarak kaydedilmiş ve kararlı hal sürtünme rejimi içerisindeki sürtünme kuvvetlerinin ortalaması alınarak ve bu değer uygulanan dik kuvvete bölünerek her bir numune için sürtünme katsayısı değerleri hesaplanmıştır. Testlerde kullanılan dik yük $5 \mathrm{~N}$ ve kompozit disklerin dönüş hızı $1100 \mathrm{dev} / \mathrm{dak}$ olarak seçilmiştir. Dönüş hızı kayma yolu içerisinde yaklaşık olarak $0.69 \mathrm{~m} / \mathrm{s}$ kayma hızına karşılık gelmektedir. Aşınma testleri $400 \mathrm{~m}$ üzerindeki kayma mesafesinde sonlandırılmış olup bu mesafe her bir numune için 10 dak'lık test süresinde elde edilmiştir. Numunelerin aşınma yolu iz merkezleri dikkate alınarak hesaplanan ortalama aşınma izi çapı yaklaşık olarak $12 \mathrm{~mm}$ 'dir. Aşınma testleri $25 \pm 2{ }^{\circ} \mathrm{C}$ 'lik sıcaklığa sahip atmosferde ve yaklaşık \%25-30 nemli ortamda tamamlanmıştır. Testlerden önce numune ve bilye yüzeyleri alkolle silinmiş ve dikkatlice kurutulmuştur. Aşınma test geometrisi şematik olarak Şekil 2 'de görüldüğü gibidir. Burada, $V\left(\mathrm{~mm}^{3}\right)$ aşınma hacmi, $K\left(\mathrm{~mm}^{3} \mathrm{~N}^{-1} \mathrm{~m}^{-1}\right)$ aşınma oranı olup, formül (1) ve (2)'den hesaplanmaktadır. Formüllerdeki, $b$ ve $d$ sırasıyla aşınma iz genişliği ve çapı (mm), $r \mathrm{Si}_{3} \mathrm{~N}_{4}$ bilyenin yarı çapı (mm), $F$ dik kuvvet (N) ve $S$ bilyenin kayma mesafesi (m)'dir. Ortalama aşınma iz genişlikleri "trapezoidal area model" ile hesaplanmış olup detaylarına [15] no'lu referanstan ulaşılabilir. Aşınma testlerinin ardından numune yüzeyleri optik mikroskop ile incelenmiş ve aşınma mekanizmaları bileşime göre yorumlanmıştır.

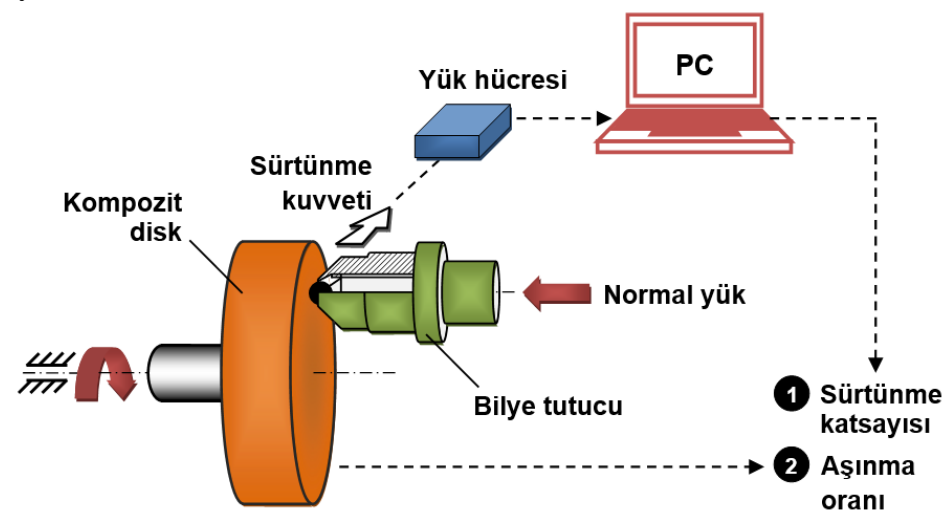

Şekil 1. Ball-on-disk aşınma test düzeneği

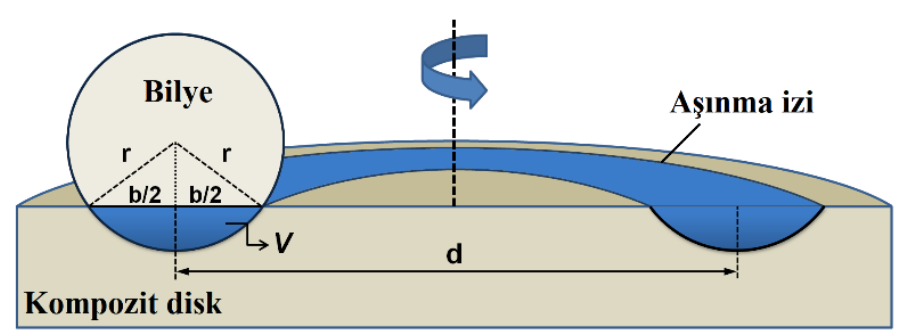

Şekil 2. Aşınma test geometrisinin şematik gösterimi

$$
\begin{gathered}
V=\left[\frac{\pi r^{2}}{180} \arcsin \left(\frac{b}{2 r}\right)-\frac{b}{2} \sqrt{r^{2}-\frac{b^{2}}{4}}\right] \pi d \\
K=\frac{V}{F S}
\end{gathered}
$$




\section{Bulgular ve Tartışma}

\subsection{Mekanik Özellikler}

Kompozitlerin eğme gerilmesi-\% uzama eğrileri ile 3-nokta eğme test sonuçları özet olarak Şekil 3'te görüldüğ̈u gibidir. Cam fiber içeriği arttıkça maksimum eğme gerilmesi de artmaktadır. Özellikle PM20 ve PM30 için eğme gerilmesi değerleri sırasıyla maksimum değerler olan 117 ve $121 \mathrm{MPa}$ 'a ulaşmaktadır. Saf PMMA nispeten sünek yapısından ve yavaş eğme hızından dolayı \%4.93'lük uzama değeri göstermiş olup, bu durum maksimum gerilme değerini arttırmış ve PM5 ile PM10'dan yüksek dayanıma çıkmasına neden olmuştur. Polimerler uzama yönünde zincir yönlenmesi göstermekte olup bu durum dayanabilecekleri mukavemetin artmasına sebep olur. 3-nokta eğme testlerinde numunelerin alt ve üst yüzeyleri sirasıyla çekme ve basma gerilmelerine maruz kalmaktadır. Özellikle gevrek yapıdaki polimerler belirli bir tepe noktasına kadar dayanım artışı gösterirler ve geri dönüş yani gerilmede azalma olmaksızın kırılırlar. Bu durum test parametreleri ve özellikle eğme hızından da etkilenmektedir. Düşük hızlarda polimerler daha yüksek gerilmelere dayanabilecek şekilde yukarıda bahsedilen yapı düzenlemesine girerler. PM0 için gerilmenin artışı bu durumla ilişkilendirilebilir. Elastiklik modüllerine bakıldığında cam fiber konsantrasyonu ile birlikte lineer bir artış dikkat çekicidir. Fiberlerin takviye edici etkisi, polimer matristen fiberlere stres transferine ve aynı zamanda bir çatlak durdurucu olarak hareket eden her bir fiberin davranışına dayanmaktadır [4]. En yüksek elastiklik modülü $7354 \mathrm{MPa}$ ile $\% 30$ cam fiber konsantrasyonuna sahip kompozitte elde edilmiştir. Uzama değerlerinde ise artan sertlikle de orantılı olarak bir azalma söz konusudur. Jang ve ark. [1] PMMA reçine ve cam fiber mat kullanarak fonksiyonel olarak kademelendirilmiş malzeme (fgm) yapısında ürettikleri kompozit eğme testi sonuçlarında da benzer şekilde cam fỉber içeriğinin artmasıyla eğme modülünün arttığını bulmuşlardır. Bununla birlikte maksimum eğme gerilmesine ise hacimce $\% 30$ cam fiber içeriğinde ulaşmışlardır. Boşluk oranına bağlansa da bu durum, eğme mukavemeti açısından bir sınır olabileceğini ve bu çalışmada da daha yüksek konsantrasyonlara çıkılsa idi bu sınırın izlenebileceğini göstermektedir.

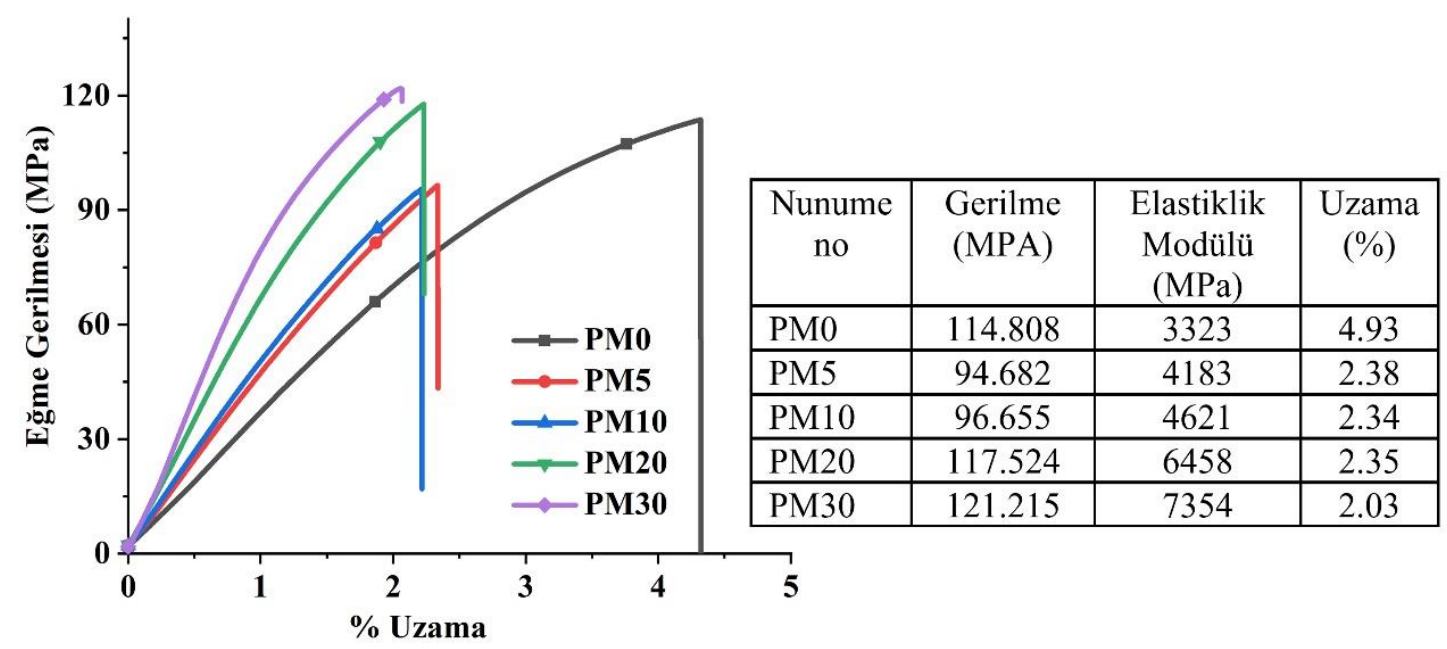

Şekil 3. Kompozitlerin eğme gerilmesi-\% uzama eğrileri ile 3-nokta eğme test sonuçlart

Kompozitlerin Shore D sertlik değerlerinin cam fiber konsantrasyonuna göre değişimi Şekil 4'te görüldüğg̈ gibidir. Saf PMMA'nın sertliğinin 81.9 olarak en düşük olduğu görülmektedir. Genel olarak artan cam fiber içeriği ile de kompozitlerin sertlik değerlerinin arttı̆ğ görülmektedir. PM20 ve PM30'un diğer konsantrasyonlara göre daha yüksek değerleri verdiği anlaşılmaktadır. Genel olarak sert bir fazın matris yapıya dahil olması kompozit sertliğinde de artış meydana getirmektedir. Sertlik değerlerindeki artışı kompozitlerin aşınma ve mekanik özellikleri üzerinde olumlu sonuçlar oluşturduğu da bilinmektedir. Aşınma sonuçlarında bahsedilecek olan PM20 ve PM30'un aşınma oranlarındaki düşüş ile bu durum ilişkilendirilebilir. 


\subsection{Aşınma Özellikleri}

Kompozitlerin sürtünme kuvveti değerlerinin zamana göre değişimi Şekil 5'te görüldüğü gibidir. 10 dak'lık testler yapıldığı için toplam 600 sn'de (400 m üzerinde) testlerin tamamlandığı grafik üzerinde görülmektedir. Doğruluk payını arttırmak için her bir izin çapı ayrı olarak ölçülmüş ve buna göre aşınma oranları tespit edilmiştir. Grafikte belirli bir süre sonunda sürtünme kuvvetlerinin sabit bir değerde kararlı hale geldiği görülmektedir. Sürtünme katsayılarının hesaplanmasında, kararlı hale geçildikten sonra test bitimine kadar tüm değerlerin ortalaması alınarak tespit edilen sürtünme kuvvetlerinin dik yüke bölünmesiyle sonuca gidilmiştir. $\mu=\mathrm{F}_{\mathrm{S}} / \mathrm{F}_{\mathrm{N}}$ formülü ile ifade edilen sürtünme katsayılarının hesabında $\mathrm{F}_{\mathrm{S}}$ sürtünme kuvvetini, $\mathrm{F}_{\mathrm{N}}(5 \mathrm{~N})$ dik yükü ifade etmektedir.

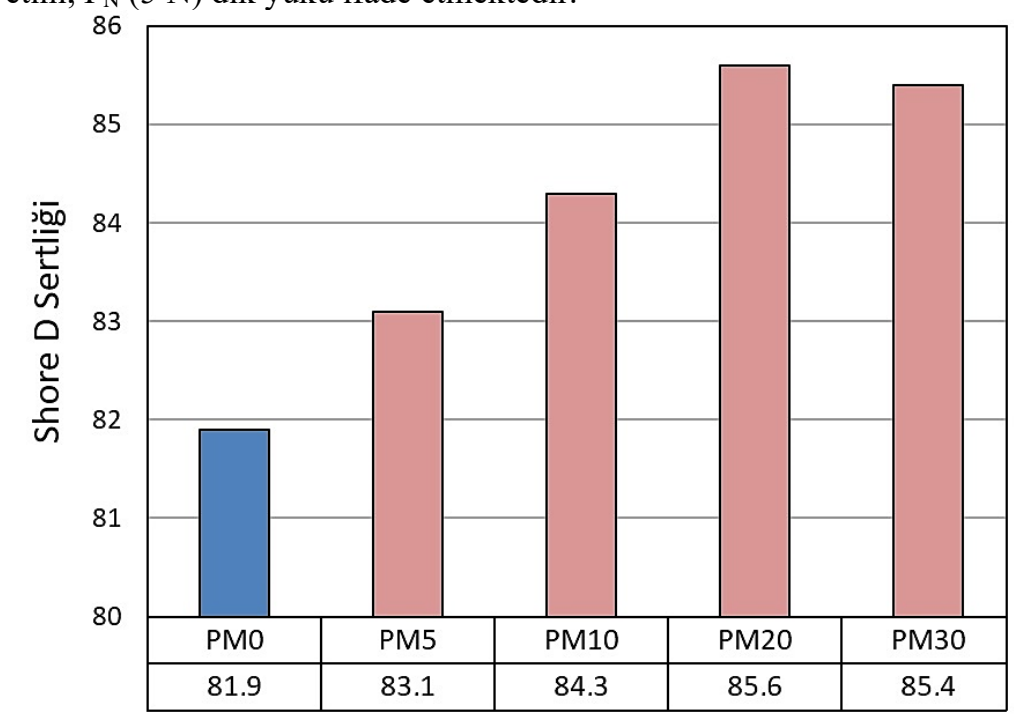

Şekil 4. Kompozitlerin Shore D sertlik değerlerinin bileşime göre değişimi

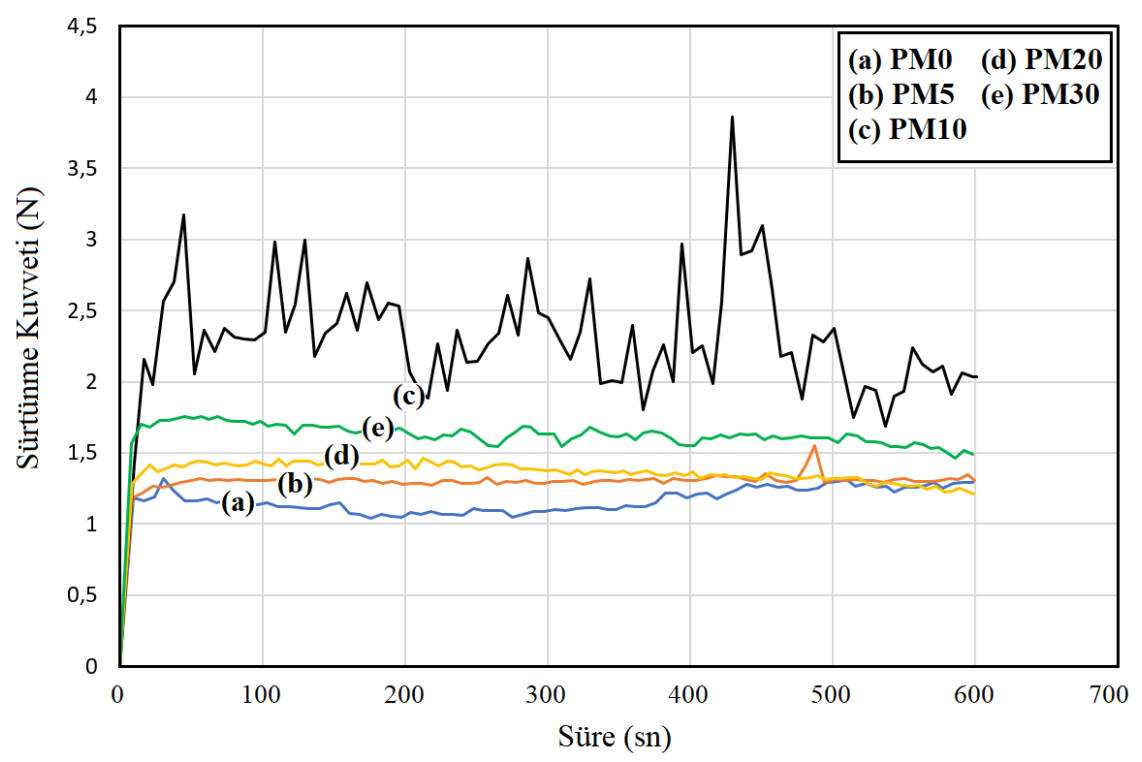

Şekil 5. Kompozitlerin sürtünme kuvveti değerlerinin zamana göre değişimi

Şekil 6'da kompozitlerin sürtünme katsayısı $(\mu)$ değerlerinin bileşime göre değişimi görülmektedir. Şekil 5 ve Şekil 6'da görüldüğü gibi sürtünme katsayısı değerlerinin saf PMMA'ya göre arttığı görülmektedir. Özellikle \%10 cam fiber konsantrasyonuna sahip kompozitte dalgalı bir sürtünme kuvveti değişimi ile yüksek bir sürtünme katsayısı değeri dikkat çekicidir. Bilindiği gibi polimerlerin ve 
kompozitlerinin sürtünme ve aşınma davranışları metal ve seramiklere göre farklılıklar gösterebilmektedir. Cam fiber içeriğinin artışı ile $\mathrm{Si}_{3} \mathrm{~N}_{4}$ bilye ile fiberler arasındaki etkileşimin sürtünme katsayısını arttırdığı düşünülmektedir. \%10 cam fiber konsantrasyonu burada kritik bir nokta olarak görülmektedir.

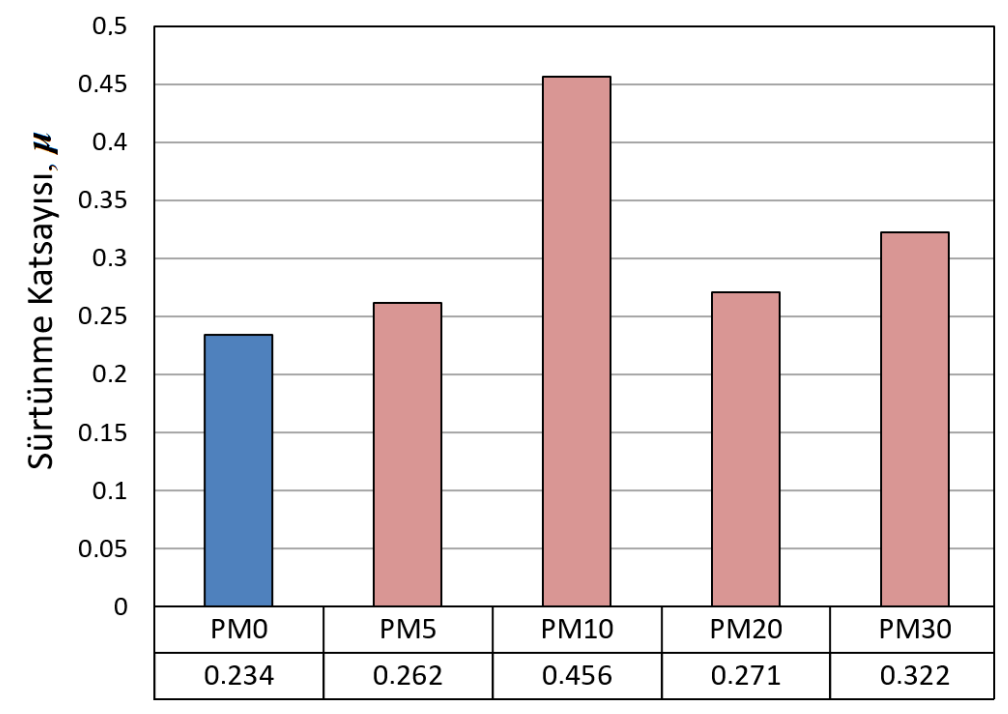

\section{Şekil 6. Kompozitlerin sürtünme katsayısı ( $\mu$ ) değerlerinin bileşime göre değişimi}

Şekil 7'de verilen kompozitlerin aşınma oranı değerlerinin bileşime göre değişimi grafiğinde de sürtünme katsayısı yüksek olduğu için PM10'un aşınma oranı değerinde de bir artış gözlenmiştir. Bununla birlikte cam fiber içeriğinin artmasıyla genel olarak aşınma direnci özelliğinin iyileştiği görülmektedir. Özellikle \%30 cam fiber konsantrasyonuna sahip PM30 kompozitinin aşınma oranında saf polimere göre \%78 oranında düşüş gözlenmiştir. Kayma aşınma direnci gerektiren uygulamalarda PMMA'dan üretilen parçaların aşınma direncinin geliştirilmesi için cam fiber kullanımının uygun olduğu bu çalışmadan çıarılabilecek bir sonuçtur. Burada özellikle \%20 konsantrasyondan sonra başarılı sonuçlara ulaşılabileceği görülmektedir. Sürtünme katsayılarının yüksek oluşunun ise uygulama esnasında dikkate alınması gereken bir konu olduğu düşünülmektedir. Düşük sürtünmenin arzu edildiği uygulamalarda cam fiber takviyeli parçalarda problemlerle karşılaşılabilir.

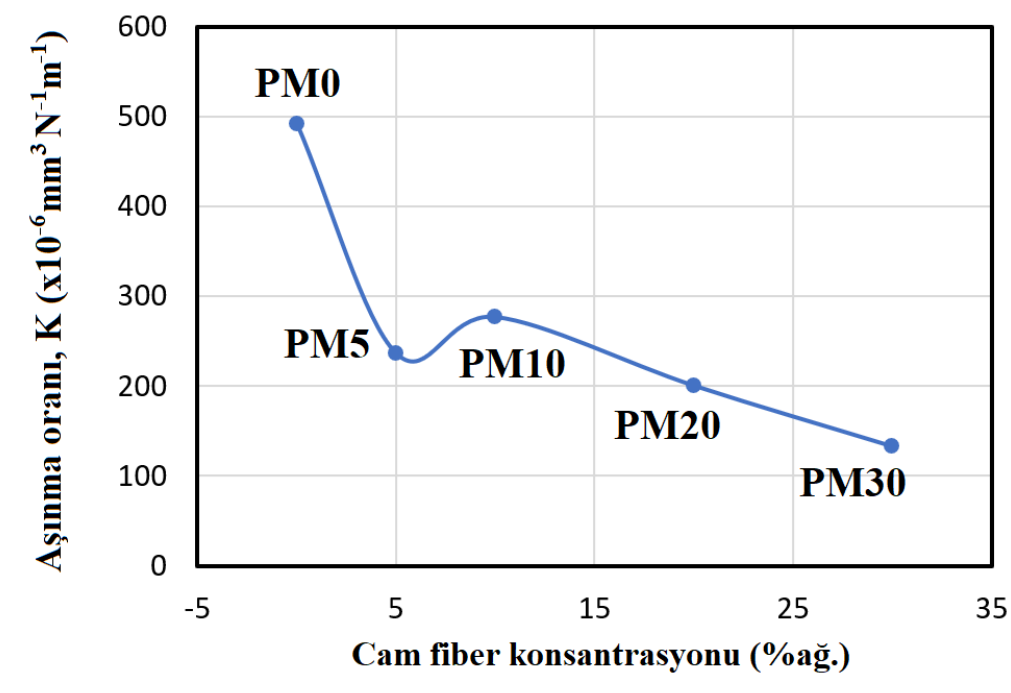

Şekil 7. Kompozitlerin aşınma oranı değerlerinin bileşime göre değisşimi 

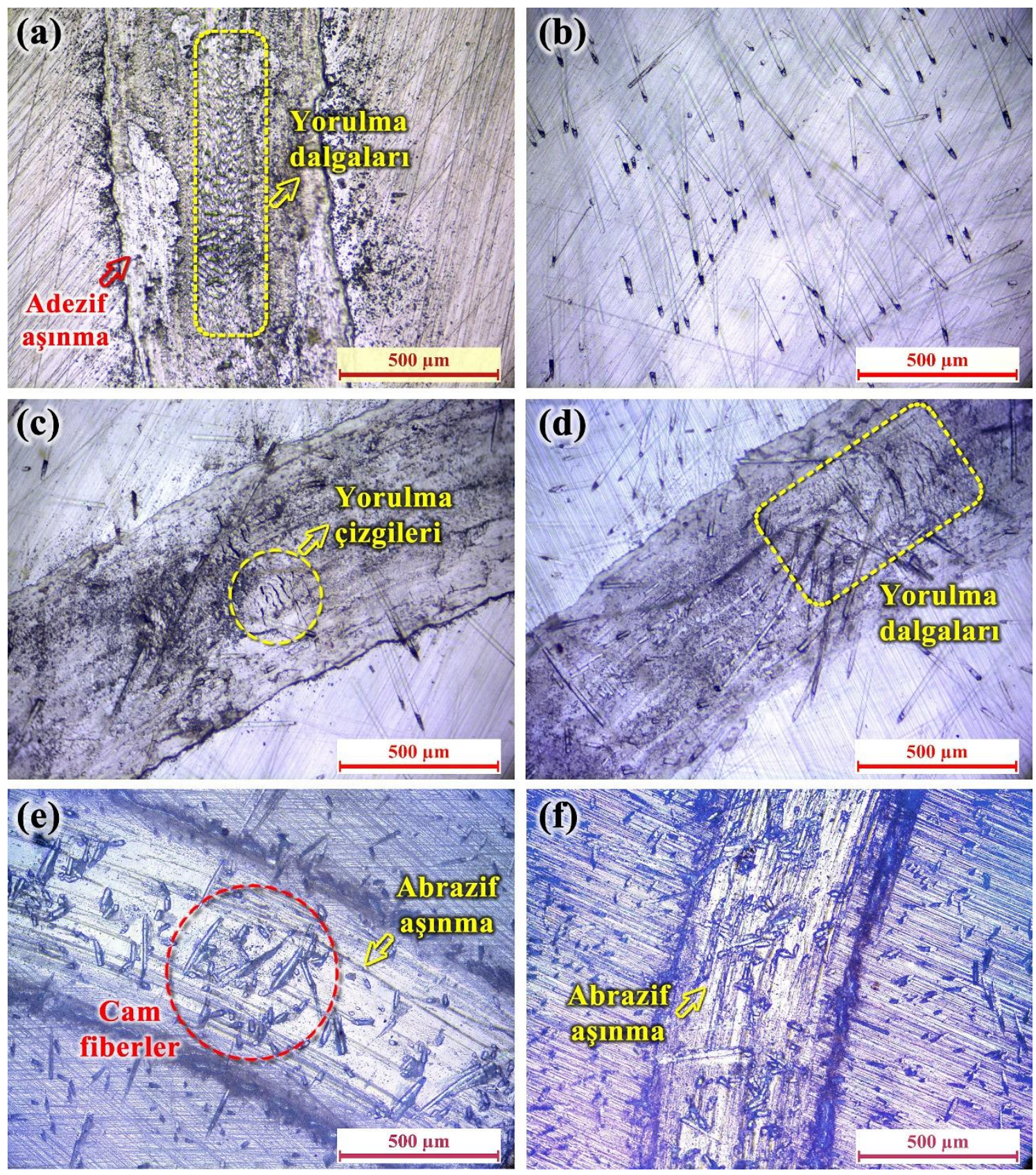

Şekil 8. Kompozitlerin aşınma izi optik mikroskop görüntüleri: (a) PM0, (b) PM5 (aşınma izi dlşındaki cam fiberlerin görüntüsü), (c) PM5, (d) PM10, (e) PM20, (f) PM30

Şekil 8'de kompozitlerin aşınma izi optik mikroskop görüntüleri görülmektedir. Polimerler daha önce de bahsedildiği gibi metal ve seramiklerden farklı aşınma karakteristiklerine sahiptirler. Viskoelastik özellikleri ve karşı malzemeye kolayca malzeme transferi yapabilmeleri genel farklılığı oluşturmaktadır [16]. Aşınma yüzeyleri üzerinde bilyenin temas ettiği bölgelerin numunelerin aşınmamış bölgelerine göre daha pürüzlü olduğu görülmektedir. Burada abrazif aşınmadan kaynaklı bilyenin kayma yönünde mikro ve makro çiziklerin oluştuğu dikkat çekicidir. Ayrıca deney düzeneği tanıtılırken açıklanan dikey test konfigürasyonu kullanılmasına rağmen aşınma izi içerisinde aşınma ürünlerinin bulunduğu görülmektedir. Bundan başka, adezif aşınma ve plastik deformasyon belirtilerine de rastlanılmıştır. Cam fiber konsantrasyonuna bağlı olarak farklı yapılar dikkat çekicidir. PM20 ve PM30 kompozitlerinin aşınma izi içerisinde daha fazla cam fiber parçaları görülmektedir. Bu kısımlarda bilyeye karşı koyan fiberlerin aşınma direncini iyileştirdiği düşünülmektedir. Saf PMMA'da adezif aşınma ile birlikte plastik deformasyon 
belirtileri görülmüştür. Sertliği nispeten düşük olan PM0, bilyenin basıncı ile sıvama şeklinde malzeme transferi göstermiş ve ilerleyen çevrimlerde bu malzeme dökülerek aşınmayı hızlandırmıştır.

Polimer kompozitlerde adezif ve abrazif aşınma tipleri ile birlikte "yorulma aşınması"” veya "yorulma dalgaları" adı verilen diğer bir tip aşınma mekanizması da görülebilmektedir. Bu tip dalgalar genellikle karşı malzeme yani bilyede bulunan bir çıkıntı veya aşınma ürününün aşınma izi içerisinden tekrarlı geçişi esnasında dalgalar meydana getirmesine dayandırılmaktadır. Yorulma aşınmasının aynı zamanda numunedeki gerilme veya kusur konsantrasyonu ile de arttığı bilinmektedir [17]. Kompozitlerin aşınma izi görüntüleri incelendiğinde yorulma aşınmasının PM0, PM5 ve PM10 kompozitlerinde baskın olduğu dikkat çekicidir. $\mathrm{Bu}$ durum, bahsedilen konsantrasyonlarda aşınma direncinin neden düşük olduğunu da açıklamaktadır. \%20 ve \%30 cam fiber konsantrasyonlarında yorulma dalgalarına rastlanılmamış olup, daha çok abrazif aşınma şeklinde makro ve mikro çizikler görülmektedir. PM20 ve PM30'un sert yapısı ile abrazif aşınma mekanizmasına olan yatkınlık artmış olup, sert segmentler bu kompozitlerin aşınma oranını azaltmıştır.

\section{Sonuçlar}

Bu çalışmada, ağırlıkça farklı yüzdelerde (\%5-10-20-30) cam fiber içeren poli(metil metakrilat) (PMMA) matrisli kompozitler ergiyik harmanlama yöntemi ile başarılı bir şekilde üretilmiş olup, mekanik ve aşınma direnci özellikleri araştırılmıştır. Bulunan sonuçlar aşağıda özetlenmektedir:

1. Kompozitlerde cam fiber içeriği arttıkça maksimum eğme gerilmesi ve elastiklik modülü de artmaktadır. Yüzde uzama değerlerinde ise azalma görülmektedir. Özellikle PM20 ve PM30 için eğme gerilmesi değerleri sırasıyla 117 ve $121 \mathrm{MPa}$ gibi yüksek değerlere ulaşmıştır. PMMA nispeten sünek yapısından dolayı \% 4.93 'lük uzama değeri göstermiş olup, bu durum zincir yönlenmesinden dolayı PM0'ın maksimum gerilme değerinin yükselmesine sebep olmuştur.

2. Kompozitlerin sertlik değerlerinde cam fiber içeriği ile lineer bir artış olduğu görülmektedir. Rijit bir malzemenin yapıya dahil edilmesi ile sertlik değerlerinde belirli bir konsantrasyona kadar artı̧̧ beklemek de doğaldır. \%30 cam fiber içeriğinden sonra düşüş olabileceği düşünülmektedir.

3. Kompozitlerde abrazif, adezif ve yorulma aşınması baskın olup, cam fiber konsantrasyonu arttıkça (özellikle $\% 20$ ve $\% 30$ 'da) yorulma aşınmasına karşı direnç iyileşmiştir. Genel olarak sürtünme katsayılarının saf PMMA'ya göre yüksek olması ile birlikte aşınma oranlarında konsantrasyona bağlı ciddi bir düşüş olduğu tespit edilmiştir. PM30 kompozitinin aşınma oranında saf polimere göre $\% 78$ oranında düşüş dikkat çekicidir. Kayma aşınma direnci gerektiren uygulamalarda PMMA'dan üretilen parçaların aşınma direncinin geliştirilmesi için \%20 ve üzerinde cam fiber takviyesinin uygun olduğu görülmektedir. Sonuç olarak, ergiyik harmanlama ile üretilen PMMA/cam fiber kompozitleri özellikle \%20-30 konsantrasyonlarında ümit vadetmekte olup, aşınma ve mekanik direnç gerektiren farklı uygulamalarda kullanım potansiyeli sunmaktadırlar.

\section{Kaynaklar}

[1] J. Jang and S. Han, "Mechanical properties of glass-fibre mat/PMMA functionally gradient composite", Composites: Part A, 30, pp. 1045-1053, 1999.

[2] T. Xie and G. Yang, "Interface and mechanical properties of poly(methyl methacrylate)fiber composites", Journal of Applied Polymer Science, 93, pp. 2478-2483, 2004.

[3] D. A. Felton and B. R. Lang, "Flexural properties of acrylic resin polymers reinforced with unidirectional and woven glass fibers", The Journal of Prosthetic Dentistry, 81(3), pp. 318-326, 1999.

[4] R. B. Fonseca, I. N. Favarão, A. V. B. Kasuya, M. Abrão, N. F. M. da Luz and L. Z. Naves, "Influence of glass fiber wt $\%$ and silanization on mechanical flexural strength of reinforced acrylics", Journal of Materials Science and Chemical Engineering, 2, pp. 1115, 2014.

[5] M. Mathew, K. Shenoy and K. S. Ravishankar, "Flexural Strength of E-glass-reinforced PMMA”, International Journal of Experimental Dental Science, 3(1), pp. 24-28, 2014. 
[6] S. Garoushi, P. K. Vallittu and L. V. J. Lassila, "Short glass fiber reinforced restorative composite resin with semi-inter penetrating polymer network matrix", Dental Materials, 23, pp. 1356-1362, 2007.

[7] P. K. Valittu and K. Narva, "Impact strength of a modified continuous glass fiberpoly(methyl methacrylate)", The International Journal of Prosthodontics, 10(2), pp. 142-148, 1997.

[8] D. S. Cousins, Y. Suzuki, R. E. Murray, J. R. Samaniuk and A. P. Stebner, "Recycling glass fiber thermoplastic composites from wind turbine blades", Journal of Cleaner Production, 209, pp. 1252-1263, 2019.

[9] S. Huang, Q. Fu, L. Yan and B. Kasal, "Characterization of interfacial properties between fibre and polymer matrix in composite materials - A critical review", Journal of Materials Research and Technology, 13, pp. 1441-1484, 2021.

[10] J. Zeng, B. Saltysiak, W. S. Johnson, D. A. Schiraldi and S. Kumar, "Processing and properties of poly(methyl methacrylate)/carbon nanofiber composites", Composites: Part B, 35, pp. 245-249, 2004.

[11] P. Threepopnatkul and C. Kulsetthanchalee, "Effect of sisal fiber on flexural and impact properties of PMMA-b-PU composites", Materials Today: Proceedings, 17, pp. 2002 2009, 2019.

[12] N. Saha, A. N. Banerjee and B. C. Mitra, "Flexural behavior of unidirectional polyethylene-glass fiber-PMMA hybrid composites", Polymers for Advanced Technologies, 6, pp. 637-642, 1995.

[13] D. Olmos, K. Bagdi, J. Mózcó, B. Pukánszky and J. González-Benito, "Morphology and interphase formation in epoxy/PMMA/glass fiber composites: Effect of the molecular weight of the PMMA", Journal of Colloid and Interface Science, 360, pp. 289-299, 2011.

[14] D. S. Cousins, C. Lowe, D. Swan, R. Barsotti, M. Zhang, K. Gleich, D. Berry, D. Snowberg and J. R. Dorgan, "Miscible blends of biobased poly(lactide) with poly(methyl methacrylate): Effects of chopped glass fiber incorporation", Journal of Applied Polymer Science, 44868, pp. 1-12, 2017.

[15] S. Savaş and A. Y. Al-Obaidi, "Influence of PP-g-MA compatibilization on the mechanical and wear properties of polypropylene/thermoplastic polyurethane blends", Tribology Transactions, 61(4), pp. 754-764, 2018.

[16] W. Österle, A. I. Dmitriev, B. Wetzel, G. Zhang, I. Häusler and B. C. Jim, "The role of carbon fibers and silica nanoparticles on friction and wear reduction of an advanced polymer matrix composite", Materials and Design, 93, pp. 474-484, 2016.

[17] N. K. Myshkin, M. I. Petrokovets and A. V. Kovalev, "Tribology of polymers: Adhesion, friction, wear, and mass-transfer”, Tribology International, 38, pp. 910-921, 2005. 